\title{
A Team Centered Grading System Based Primarily On The Team's Performance
}

\author{
Robert Martinazzi \\ Engineering Technology Division \\ University of Pittsburgh at Johnstown \\ Johnstown, PA 15904
}

\begin{abstract}
One of the current expectations of industry requires universities to provide technically competent engineering professionals capable of immediate assimilation into a team based working environment. The only practical means of affording students a team based learning experience involves having students function as a team member in a course (s) taken during their college experience.

One of the major challenges of using student teams focuses on providing the student team with some definite "reward" for their collective performance while ensuring the integrity of individual learning. Without a grading component serving as a team "reward", little incentive exists for students to participate fully and learn the underlying concepts, skills, and synergistic potential associated with being a member of a high performance team.
\end{abstract}

This paper presents a method for course grading based primarily on the student team's performance. It resulted from numerous attempts to have students accept "ownership" for developing the method of determining the course grade because "a basic principle of the team concept is to create a sense of job ownership." (1) The paper explains how each team member's individual performance is integrated with the team's performance to produce the final course grade. The final course grade received by the student is weighted so approximately two-thirds of it results from the team's effort with the remainder derived solely from the student's individual performance.

\section{Introduction}

Experimentation with student learning teams began several years ago and it was based on team models developed in a private consulting practice. Researching industrial team models led to an analogous set of similar requirements associated with developing student learning teams. One of these requirements focused directly on team "rewards". Unless team members receive a "reward" based on their collective effort very little incentive exists for individuals to cooperate and seek the synergistic level indicative of high performance teams.

When translating this realization to academia and into a collaborative learning environment, any attempt to use student learning teams must provide for a "reward" based on the team's collective performance. The described method evolved over the span of several years with substantial input and feedback from the students themselves thus providing the "ownership" component necessary for acceptance by the teams.. While students welcomed the "team" opportunity, they also expressed interest in and concern about their ability to demonstrate their own individual learning. Listening to and incorporating their suggestions into the method was a critical factor in the model. The method now has the wholehearted endorsement of the students choosing to take the class using a team based format.

\section{Background}

When experimentation with team based collaborative learning began the primary focus centered on team building skills. Since students had essentially no experience with being on a technical team, time had to be spent acquainting them with the various elements associated with building a team. (2) Subsequently, student teams developed mission statements, defined roles, developed problem solving methodologies and worked on improving their interpersonal skills. Student also initially agreed that periodic examinations administered throughout the semester be the most appropriate and logical vehicle for evaluating and rewarding the collective performance of the team. From their perspective the course examinations would reflect how well the team worked together to solve the problems on the exam.

Each team member was given a copy of the examination and the team members were permitted to openly discuss each problem and the method of solution. For grading purposes, each team turned in only one completed examination. The resulting test score was then assigned to each team member. Consequently, at the end of the semester every member team received the identical grade for the course.

While not totally unacceptable this method of assigning a grade for the course had some definite room for improvement according to the student evaluations. While wanting to preserve a major team grade component, the students suggested several ways to incorporate the individual learning effort into the course grade. As students became familiar with team building concepts they understood some of the latest research which suggests team members do not easily take responsibility for the performance of others, nor lightly let them assume responsibility for us. Overcoming such resistance requires the rigorous application of team basics-accountability, commitment and skills. ${ }^{(3)}$ 
They viewed individual effort as a necessary incentive to keep all team members active and engaged in the learning process. Thus the "kisen" or continuous improvement process resulted in the quest to develop an equitable course grading system containing both a team and individual grading component.

\section{Concept Development \& Implementation}

The first major change, suggested by the students and implemented the following year focused on the examinations themselves. Each examination would have a total of four (4) problems and these would be divided into two sections. The first section consists of one (1) problem to be worked by every team member on an individual basis. Examinations cover a variety of subject areas and the students are not told which specific problem area they will be tested on individually. Consequently, students are personally responsible for being fluent in all of the subject areas covered by the examinations. From a test administration standpoint, one fourth of the examination time is allotted for the individual problem. This individually solved problem is given at the beginning of the testing period.

The second part of the examination contains three (3) problems which the team works together in a manner discussed previously. After completing this major part of the examination, only one (1) copy of it is turned in for grading. The score received for this portion of the test is assigned to each team member. Thus, the student's exam score is a derivative of their individual performance $(25 \%$ or one problem) and the team's score (75\% or three problems). Table 1 contains a breakdown of both the team and individual performance scores for "Engineering Statics" taught during the Fall 96-1 semester. _The first number under each "CDOPE" or examination represents the team's score for that portion of the test. This team score is assigned to every team member. The second number reflects each team member's individual score for that segment of the test. These are added together to produce the final test results.

TABLE 1

ENGINEERING STATICS -( FALL 96-1)

$\underline{\text { Team/Student }}$ CDOPE-1 $*$ CDOPE-2 $\quad \underline{\text { CDOPE-3 }}$ CDOPE-4

Developmental Engineers:
A $\quad 75+22=97$
$61+10=71$
$75+10=85$
$70+25=95$
$62+17=79$
B $75+20=95$
$61+0=61$
$75+13=88$
$70+25=95$
$62+12=74$
C
$75+22=97$
$61+15=76$
$75+25=100$
$70+25=95$
$62+11=73$

\section{Uncertainties:}

$\begin{array}{llllll}\mathbf{D} & 63+20=83 & 61+17=78 & 68+25=93 & 70+25=95 & 75+22=97 \\ \mathbf{E} & 63+17=80 & 61+10=71 & 68+25=93 & 70+21=91 & 75+11=86 \\ \mathbf{F} & 63+25=88 & 61+25=86 & 68+25=93 & 70+25=95 & 75+18=93\end{array}$

X - Force:

$\begin{array}{clllll}\mathbf{G} & 63+22=85 & 50+10=60 & 75+20=95 & 70+25=95 & 75+17=92 \\ \mathbf{H} & 63+12=75 & 50+5=55 & 75+25=100 & 70+5=75 & 75+12=87 \\ \mathbf{I} & 63+25=88 & 50+19=69 & 75+25=100 & 70+10=80 & 75+18=93\end{array}$

Total Package:

$\begin{array}{llllll}\mathbf{J} & 60+20=80 & 52+25=77 & 75+25=100 & 75+25=100 & 75+25=100 \\ \mathbf{K} & 60+18=78 & 52+10=62 & 75+25=100 & 75+20=95 & 75+25=100 \\ \mathbf{L} & 60+25=85 & 52+17=69 & 75+25=100 & 75+25=100 & 75+18=93\end{array}$

* "CDOPE"stands for "Clear Demonstration Of Professional Excellence" another name for "Examination" 
This initial iteration of the search for an equitable team/ individual grading system now contained a twenty-five (25\%) percent individual effort component. Course evaluations by students favored this new method which emphasized individual accountability and responsibility. Last year the students continued to embrace the "ownership" mentality by suggesting a critical refinement to the individual component of the grading system.

Quizzes, dreaded by most students, were suggested numerous times in several other team taught classes as an additional method to emphasize the necessity of individual accountability for learning. Team learning was occurring because the teams did meet regularly. However, not all team members were equal contributors to the team study periods. ${ }^{(4)}$ Individual quizzes were viewed as an effective instrument to curtail this unsatisfactory behavior by certain team members.

Beginning in the Fall 96-1 semester, four (4) unannounced and individually taken quizzes were administered to the class. The collective score of the quizzes became equivalent to one examination. No quizzes were "dropped" when the exam equivalent score was computed. Student evaluations indicated this method of determining the course grade reflected an equitable distribution between the individual and team effort and, most importantly, held the vast majority of students personally accountable for learning the material. Table 2 reflects the individual quiz scores for the students listed in Table 1. The "EXAM EQUIVAL" column is the sum of the four quiz scores which constitutes the equivalent of one (1) examination. Table 3 contains several columns of importance in determining the student's final grade. "CDOPE TOTAL" represents the sum of the five (5) CDOPE scores in Table 1. The "EXAM EQUIV" number is taken directly from Table 2. The "TOTAL POINTS/\%" column is the sum of the two previous columns along with its percentage equivalent while the "GRADE" column represents the grade received for the course.

TABLE 2

ENGINEERING STATICS - (FALL-96-1)

\section{$\underline{\text { Team/Student QUIZ } 1 \text { QUIZ } 2}$ QUIZ 3 QUIZ 4 EXAM EQUIVAL *}

Developmental Engineers:

$\begin{array}{lrrrrr}\mathbf{A} & 20 & 15 & 16 & 15 & 66 \\ \mathbf{B} & 0 & 13 & 16 & 15 & 44 \\ \mathbf{C} & 5 & 15 & 18 & 15 & 53\end{array}$

Uncertainties:

$\begin{array}{llllll}\mathbf{D} & 18 & 13 & 18 & 25 & 74 \\ \mathbf{E} & 17 & 15 & 18 & 25 & 75 \\ \mathbf{F} & 21 & 15 & 18 & 25 & 79\end{array}$

X - Force:

$\begin{array}{rrrrrr}\mathbf{G} & 25 & 15 & 20 & 13 & 73 \\ \mathbf{H} & 17 & 18 & 25 & 13 & 73 \\ \mathbf{I} & 25 & 15 & 25 & 13 & 78\end{array}$

Total Package:

$\begin{array}{llllll}\mathbf{J} & 25 & 25 & 20 & 25 & 95 \\ \mathbf{K} & 10 & 18 & 18 & 25 & 71 \\ \mathbf{L} & 25 & 18 & 16 & 25 & 84\end{array}$

* "EXAM EQUIVAL" is the sum of the four individual quiz scores. 
TABLE 3

ENGINEERING STATICS -(FALL 96-1)

Student CDOPE TOTAL EXAM EQUIV TOTAL POINTS/ \% GRADE

Developmental Engineers:

$\begin{array}{lllll}\mathbf{A} & 427 & 66 & 493 / \mathbf{8 2 . 2} * & \mathbf{B} \\ \mathbf{B} & 413 & 44 & 457 / \mathbf{7 6 . 2} & \mathbf{C} \\ \mathbf{C} & 441 & 53 & 494 / \mathbf{8 2 . 3} & \mathbf{B}\end{array}$

Uncertainties:

$\begin{array}{lllll}\mathbf{D} & 446 & 74 & 520 / 86.7 & \text { B } \\ \mathbf{E} & 421 & 75 & 496 / \mathbf{8 2 . 7} & \mathbf{B} \\ \mathbf{F} & 455 & 79 & 534 / \mathbf{8 9 . 0} & \mathbf{B}\end{array}$

X - Force:

$\begin{array}{ccccc}\mathbf{G} & 427 & 73 & 500 / \mathbf{8 3 . 3} & \mathbf{B} \\ \mathbf{H} & 387 & 73 & 460 / \mathbf{7 6 . 7} & \mathbf{C} \\ \mathbf{I} & 425 & 78 & 503 / \mathbf{8 3 . 8} & \mathbf{B}\end{array}$

Total Package:

$\begin{array}{lllll}\mathbf{J} & 457 & 95 & 552 / \mathbf{9 2 . 0} & \mathbf{A} \\ \mathbf{K} & 435 & 71 & 506 / \mathbf{8 4 . 3} & \mathbf{B} \\ \mathbf{L} & 447 & 84 & 531 / \mathbf{8 8 . 5} & \mathbf{B}\end{array}$

* “\%" derived by taking "Total Points" and dividing it by the total possible points (600) and multiplying by 100\%. Total possible points is based on 500 points from CDOPE's and 100 points from QUIZZES.

\section{Conclusions}

When using student learning teams it is essential to provide them with as much latitude as possible in determining the method for grading the course. Incidentally, at the beginning of each semester the students are presented with the "lessons learned" from previous teams and are given the opportunity to modify the grading method provided their suggestions enhance both team learning and individual accountability. As an example, students in the current semester are being administered five (5) unannounced quizzes with the lowest quiz score being dropped.

Because of the generic nature of this model, it is applicable to any problem solving class employing student learning teams. It has been successfully implemented in Engineering Statics, Dynamics and Engineering Economics classes.

The end result of the course grades received by the students has been very interesting. A "compaction" of grades occurred resulting in very few "A"s or "D"s or "F"s in the course. Both the academically stronger and weaker student's destiny are linked together because of the interdependent nature of the team. This "link" tends to detract from the stronger student's performance "potential" while enhancing that of the weaker team member.

However, this is clearly pointed out at the beginning of the semester prior to the students deciding to be on a team or not. Inevitably, especially with the academically stronger students, they still opt for the team experience because they see the definite benefits of that opportunity. A review of student comments on several course evaluations did not reveal any negative statements indicating that team grading was not beneficial to the students who chose to be on a team.

Another observation involves the "standard of performance" or scale for determining the course grade. After numerous years of teaching a subject the instructor should possess the historical data to establish the "standard of performance" by which the teams will be evaluated and a course grade assigned. With the "standard of performance" announced and written down, teams are encouraged not to 
compete but rather cooperate with each other since they are competing against the "standard of performance" for their course grade. Understanding this has proven very beneficial to the teams because it unites them against an "external" competitor namely, the "standard of performance".

In summary, the method described in this paper addresses learning from both the team's and individual's perspectives. Team and individual responsibility and accountability are integrated in an equitable proportion. $62.5 \%$ of the final course grade is based on the team's collective performance while the remaining $37.5 \%$ is a direct result of each team member's individual performance. As noted throughout this paper, the method evolved from the students input and feedback. This resulted in team members being motivated and feeling "empowered" because they are listened too and taken seriously in an area of utmost importance to them - their course grade.

\section{References}

1) Wellins, R.S., Byham, W.C., Dixon, G.R., "Inside Teams: How 20 World Class Organizations are Winning Through Teamwork", Jossey-Bass, San Francisco, CA, 1994.

2) Cordes, D., Parker, J., Nikles, D., Hopenwasser, A., Laurie, C., Izatt, J., "Teaming In Technical Courses", Proceeding from 1995 ASEE/IEEE Frontiers in Education Conference.

3) Katzenback, J.R. and Smith D.K., "The Wisdom of Teams: Creating The High Performance Organizations", Harper Business Publishers, Inc., New York, NY.

4) Brown, R.W., "Autorating: Getting Individual Marks From Team Marks and Enhancing Teamwork", Proceeding from 1995 "ASEE/IEEE Frontiers in Education Conference. 